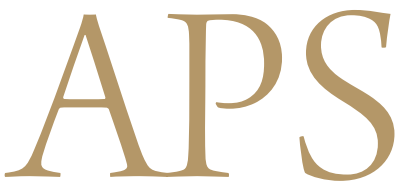

Archives of Plastic Surgery

\title{
Augmentation Mammaplasty Using Implants: A Review
}

\author{
Susumu Takayanagi \\ Division of Plastic Surgery, Mega Clinic, Osaka, Japan
}

One of the techniques for augmentation mammaplasty is the procedure using implants. Even though this technique has been used for many years, there are still several controversial issues to be discussed and overcome for patient safety. In this review article, capsular contracture, leak or rupture of the implants, possible systemic disease, relation with breast cancer, and recent problems with Poly Implant Prothese implants are described and discussed.

Keywords Mammaplasty / Contracture / Implants / Silicones / Breast neoplasms

Correspondence: Susumu Takayanagi

Division of Plastic Surgery, Mega

Clinic, 1-18-5 Higashinakajima,

Higashiyodogawa-ku, Osaka

533-0033, Japan

Tel: $+81-6-6370-0112$

Fax: +81-6-6327-0584

E-mail:info@mega-clinic.com

No potential conflict of interest relevant to this article was reported.

\section{INTRODUCTION}

There are several types of augmentation mammaplasty: fat injection, hyaluronic acid injection, and procedures using implants. Fat injection is one technique of breast augmentation. However, it is often difficult to create a large volume change through fat injection and patients may require several sessions before they are satisfied with the result. Also, it may cause cyst formation, which may obstruct the detection of breast cancer.

Hyaluronic acid injection is another procedure for augmentation mammaplasty. However, this is an absorbable material, and it is necessary to repeat the injection to maintain breast volume. Also, any kind of breast filler injection is prohibited in France due to the possible hindrance posed in identifying breast cancer.

Though breast augmentation using implants is still the most reliable technique, there are still problems or controversial issues to overcome. In this article, several issues are discussed in the interest of patient safety.

\section{BREAST CANCER}

Many studies using animals to detect whether or not silicone causes cancer have been performed. Among these, one reported that silicone implants cause fibrosarcoma in rats [1]. However, silicone implants have never caused fibrosarcoma in other animals $[2,3]$. The incidence rate of fibrosarcoma in the US had not increased since they started using silicone implants [4].

Many reports have also addressed the relationship between breast cancer and augmentation mammaplasty using implants. Most of them report that there is no increased rate of breast cancer in patients with augmentation mammaplasty $[5,6]$. On the contrary, several studies have reported that the rate of breast cancer is actually lower in patients with augmentation mammaplasty $[7,8]$. These studies argue that the lower incidence rate of breast cancer is probably due to the lower calorie intake of patients who wish to have augmentation mammaplasty. These patients, being on the thinner side, do not have a tendency toward breast cancer.

One of the recent issues regarding breast cancer is anaplastic large cell lymphoma (ALCL), a very rare type of peripheral T-

Copyright (ㅇ 2012 The Korean Society of Plastic and Reconstructive Surgeons

This is an Open Access article distributed under the terms of the Creative Commons Attribution Non-Commercial License (http://creativecommons.org/

licenses/by-nc/3.0/) which permits unrestricted non-commercial use, distribution, and reproduction in any medium, provided the original work is properly cited.

www.e-aps.org 
cell lymphoma. The first three cases were reported by Duvic et al. [9]. Other reports showed that ALCL occurred after using both silicone implants and saline implants which have a silicone outer shell $[10,11]$. In total, 22 cases have been reported.

The odds ratio of ALCL in the breast associated with silicone implants was reported to be 18.2, although the absolute risk was exceedingly low due to the rare occurrence of ALCL [12]. Also, the fact that ALCL was found just at the surface of the implant in most reported cases suggests that the ALCL was caused by the silicone implant $[10,11]$.

However, given that only 22 cases of ALCL have been reported, further epidemiological studies are necessary to determine the real cause of ALCL.

\section{SYSTEMIC DISEASE}

Patients with augmentation mammaplasty using silicone implants may have symptoms of arthritis, fever, sclerosis of the skin, Raynaud's disease, or enlargement of the lymph nodes. Some doctors attribute this to human adjuvant disease, which is induced by silicone [13].

Silicone implants have been used in about 500 million patients worldwide and about 100 cases of imunological disease have been reported. In the US, silicone implants have been used in about 200 million patients, and 28 cases of immunological disease have been reported. However, these incidence rates are at the same level as those for women without augmentation mammaplasty, and there is no statistical relationship between augmentation mammaplasty and immunological disease $[14,15]$.

Brody et al. [16] reported that silicone implants do not induce immunological disease and as the human adjuvent disease does not exist, he recommends not using this medical term. However, several recent studies have demonstrated multiple proinflammatory serum proteins adhering to the surface of silicone implants, and this suggests that they are correlated with the development of massive capsular fibrosis and contracture, and perhaps also with the onset of autoimmune disease [17,18].

As long-lasting implants in patients may cause an increase in fibrosis to the point of capsular contracture, they may also stimulate an anti-self response, leading to the development of autoimmune disease [19]. Further study is required to clarify whether these parameters are truly correlated with the occurrence of systemic disease.

\section{CAPSULAR CONTRACTURE}

Capular contracture is one of the main complications of augmentation mammaplasty. Several causes of capsular contracture have been reported: bleeding or hematoma, minor infection, and leakage of silicone. Many techniques have been reported for avoiding capsular contracture, among them, precise hemostasis, perfect sterile technique, placement of the implant beneath the pectoralis major muscle, using saline implants, and breast massage [20-23]. Unfortunately, none of these techniques are preventative measures for avoiding capsular contracture.

The author agrees that the textured surface implant provides better anti-capsular contracture results and recommends the use of textured surface implants for augmentation mammaplasty [24-27]. The author also recommends against breast massage for three months after surgery. Relatively new phenomena regarding capsular contracture are double capsule and late seroma [28].

Double capsules are only seen with Biocell textured surface implants. This phenomenon is not seen in smooth saline or smooth silicone gel implants. Other types of textured surface implants never show this problem either. As the Biocell texturing increases the capsular contracture rate, further study is necessary to know what texture surface should be used to prevent capsular contracture and resulting late seroma.

\section{RUPTURE AND LEAK OF IMPLANT}

Leak or rupture of the implant may occur. When these problems occur with the hydrogel implant, two types of symptoms will become obvious. If the leak is very small in volume, the breast will gradually become smaller without any pain. If the leak is large in volume or if rupture of the implant occurs, the breast will become swollen, with or without pain and redness of the breast skin.

When a saline implant is used, leaks or ruptures of the implant will cause decreased volume of the breast. Patients who have saline breast implants should be informed that they must have a leaking implant replaced with a new implant within several days after noticing a volume change of their breasts. This is to prevent a change in the breast volume.

Otherwise, the capsule may shrink and replacement surgery will become difficult. If the patient does not want to have new implants and just wants to remove the ruptured saline implant, she can have surgery any time after noticing the problem.

When a rupture or leak of silicone implants takes place, the patient does not notice the problem in most cases. Therefore, patients with silicone implants should be advised to examine their breast implants together with the breast tissue once every year following the surgery.

Rupture or leak of the silicone implant may be caused by closed capsulotomy, mammography, or by accident. Also aging or weakness of the outer shell of the implant may cause the problem 
[29-31].

When the rupture or leak of the silicone implant occurs, it will often occur only inside the capsule. In some cases, however, it may spread to the surrounding tissue through the capsule. The leaked silicone may cause cyst formation, inflammation, pain of the shoulder or upper arm, firmness of the skin, erythema, and/ or edema $[30,32]$.

Recently, cohesive silicone gel implants have been made available. However, the grade of the cohesive quality, and it is not clear that the cohesive silicone will never leak out from the outer shell in the future. Even when the cohesive silicone implant is used, patients should be advised to have the implant and surrounding breast tissue examined every year.

\section{EXAMINATIONFORBREAST CANCER}

Patient safety is the most important factor in every kind of surgical procedure. When patients have implants in their breasts, examination of the breast implants and breast tissue should be performed every year following the surgery.

Silicone implants can hinder X-ray examinations due to their low transparency. In some cases, calcification around the implant may be found and this can stand in the way of a thorough examination of the breast tissue [33].

However, there are several reports that well-experienced doctors do not have any problems detecting breast cancer in implant augmented breasts $[7,34,35]$.

Several procedures should be combined to obtain correct diagnosis during implant augmented breast examinations [36]. Patients should also be informed that mammography sometimes damages the implant surface, which may lead to leaks or ruptures.

\section{PROBLEMS WITH PIP IMPLANTS}

Recently, problems with Poly Implant Prothese (PIP) implants have been publicized. The silicone used in this brand of implants was industrial grade as opposed to medical grade. The silicone inside the PIP implants was not pure silicone; these implants may have contained several other foreign materials and/or they may have been contaminated.

Thus, PIP implants are not safe implants, and they should be removed immediately if patients have received them. Moreover, the capsule around the implant should be removed simultaneously. Also, if it is discovered that they have enlarged lymph nodes, these should also be removed at the same time.

\section{REFERENCES}

1. Dunn KW, Hall PN, Khoo CT. Breast implant materials: sense and safety. Br J Plast Surg 1992;45:315-21.

2. Hoopes JE, Edgerton MT Jr, Shelley W. Organic synthetics for augmentation mammaplasty: their relation to breast cancer. Plast Reconstr Surg 1967;39:263-70.

3. Lilla JA, Vistnes LM. Long-term study of reactions to various silicone breast implants in rabbits. Plast Reconstr Surg 1976; 57:637-49.

4. May DS, Stroup NE. The incidence of sarcomas of the breast among women in the United States, 1973-1986. Plast Reconstr Surg 1991;87:193-4.

5. De Cholnoky T. Augmentation mammaplasty. Survey of complications in 10,941 patients by 265 surgeons. Plast Reconstr Surg 1970;45:573-7.

6. Harris HI. Survey of breast implants from the point of view of carcinogenesis. Plast Reconstr Surg Transplant Bull 1961; 28:81-3.

7. Deapen DM, Pike MC, Casagrande JT, et al. The relationship between breast cancer and augmentation mammaplasty: an epidemiologic study. Plast Reconstr Surg 1986;77: 361-8.

8. Deapen DM, Brody GS. Augmentation mammaplasty and breast cancer: a 5-year update of the Los Angeles study. Plast Reconstr Surg 1992;89:660-5.

9. Duvic M, Moore D, Menter A, et al. Cutaneous T-cell lymphoma in association with silicone breast implants. J Am Acad Dermatol 1995;32:939-42.

10. Keech JA Jr, Creech BJ. Anaplastic T-cell lymphoma in proximity to a saline-filled breast implant. Plast Reconstr Surg 1997;100:554-5.

11. Gaudet G, Friedberg JW, Weng A, et al. Breast lymphoma associated with breast implants: two case-reports and a review of the literature. Leuk Lymphoma 2002;43:115-9.

12. de Jong D, Vasmel WL, de Boer JP, et al. Anaplastic large-cell lymphoma in women with breast implants. JAMA 2008;300: 2030-5.

13. Baldwin CM Jr, Kaplan EN. Silicone-induced human adjuvant disease? Ann Plast Surg 1983;10:270-3.

14. Andersen B, Hawtof D, Alani H, et al. The diagnosis of ruptured breast implants. Plast Reconstr Surg 1989;84:903-7.

15. Shons AR, Schubert W. Silicone breast implants and immune disease. Ann Plast Surg 1992;28:491-9.

16. Brody GS, Conway DP, Deapen DM, et al. Consensus statement on the relationship of breast implants to connectivetissue disorders. Plast Reconstr Surg 1992;90:1102-5.

17. Backovic A, Huang HL, Del Frari B, et al. Identification and 
dynamics of proteins adhering to the surface of medical silicones in vivo and in vitro. J Proteome Res 2007;6:376-81.

18. Backovic A, Wolfram D, Del-Frari B, et al. Simultaneous analysis of multiple serum proteins adhering to the surface of medical grade polydimethylsiloxane elastomers. J Immunol Methods 2007;328:118-27.

19. Bassetto F, Vindigni V, Scarpa C, et al. Breast prostheses and connective tissue disease (CTD): myth or reality? Aesthetic Plast Surg 2010;34:257-63.

20. Asplund O. Capsular contracture in silicone gel and salinefilled breast implants after reconstruction. Plast Reconstr Surg 1984;73:270-5.

21. Capozzi A. Clinical experience with Heyer-Schulte inflatable implants in breast augmentation. Plast Reconstr Surg 1986;77:772-8.

22. Chang L, Caldwell E, Reading G, et al. A comparison of conventional and low-bleed implants in augmentation mammaplasty. Plast Reconstr Surg 1992;89:79-82.

23. Schuster DI, Lavine DM. Nine-year experience with subpectoral breast reconstruction after subcutaneous mastectomy in 98 patients utilizing saline-inflatable prostheses. Ann Plast Surg 1988;21:444-51.

24. Takayanagi S. A general overview with regard to the use of synthetic implants for breast reconstruction. Jpn J Plast Reconstr Surg 1994;37:729-36.

25. Coleman DJ, Foo IT, Sharpe DT. Textured or smooth implants for breast augmentation? A prospective controlled trial. Br J Plast Surg 1991;44:444-8.

26. Ersek RA. Rate and incidence of capsular contracture: a comparison of smooth and textured silicone double-lumen breast prostheses. Plast Reconstr Surg 1991;87:879-84.
27. Hakelius L, Ohlsen L. A clinical comparison of the tendency to capsular contracture between smooth and textured gelfilled silicone mammary implants. Plast Reconstr Surg 1992; 90:247-54.

28. Hall-Findlay EJ. Breast implant complication review: double capsules and late seromas. Plast Reconstr Surg 2011;127: 56-66.

29. de Camara DL, Sheridan JM, Kammer BA. Rupture and aging of silicone gel breast implants. Plast Reconstr Surg 1993;91:828-34.

30. Erdmann MW, Asplund O, Bahnasy N. Transcutaneous extravasation of silicone following breast augmentation. $\mathrm{Br} \mathrm{J}$ Plast Surg 1992;45:479-80.

31. Nelson GD. Complications of closed compression after augmentation mammaplasty. Plast Reconstr Surg 1980;66:71-3.

32. Sanger JR, Matloub HS, Yousif NJ, et al. Silicone gel infiltration of a peripheral nerve and constrictive neuropathy following rupture of a breast prosthesis. Plast Reconstr Surg 1992;89:949-52.

33. Rolland C, Guidoin R, Marceau D, et al. Nondestructive investigations on ninety-seven surgically excised mammary prostheses. J Biomed Mater Res 1989;23:285-98.

34. Eklund GW, Busby RC, Miller SH, et al. Improved imaging of the augmented breast. AJR Am J Roentgenol 1988;151: 469-73.

35. Mitnick JS, Harris MN, Roses DF. Mammographic detection of carcinoma of the breast in patients with augmentation prostheses. Surg Gynecol Obstet 1989;168:30-2.

36. Hayes H Jr, Vandergrift J, Diner WC. Mammography and breast implants. Plast Reconstr Surg 1988;82:1-8. 